\title{
Children's Life Satisfaction and Satisfaction with School Travel
}

\author{
Margareta Friman ${ }^{1}$ (D) Jessica Westman ${ }^{1}$. \\ Lars E. Olsson ${ }^{1}$
}

\begin{abstract}
To understand children's experiences of their daily travel, and the consequences of these experiences, it is essential that we directly address children. The Satisfaction with Travel Scale (STS) is a self-report instrument consisting of nine items divided into three subscales - two reflecting affective travel experiences and one reflecting cognitive travel experiences. The present study has two aims: (i) to examine the psychometric properties of a child version of the STS (referred to as the STS-C), and (ii) to test a potentially positive relationship between travel satisfaction and life satisfaction among children, something which has been found among adults. Three hundred and forty-five children completed the STS-C, life satisfaction scales, and sociodemographic variables. Analyses using Partial Least Square structural equation modelling revealed that the STS-C was internally reliable, had a sound construct validity, and confirmed a one-factor second-order measurement model with three first-order constructs (subscales). Furthermore, children's satisfaction with school travel was also significantly related to their life satisfaction as measured by their satisfaction with: themselves, school experiences, friendships, family, and living environment. The relationship between travel satisfaction and life satisfaction varied between modes, whereby it was stronger among those who traveled by active modes than those who traveled by school bus or car. Younger children and boys were more satisfied with their travel to school, something which also had an indirect effect on their life satisfaction.
\end{abstract}

Keywords Satisfaction with travel scale · Children's travel · Children's life satisfaction · Affect $\cdot$ School travel

Margareta Friman

Margareta.Friman@kau.se

1 CTF Service Research Center and Department of Social and Psychological Studies, Karlstad University, SE-651 88 Karlstad, Sweden 


\section{Introduction}

Children's travel experiences have been investigated by scholars in diverse areas, e.g. urban studies, transportation, tourism, psychology, and public health. Within these research streams, studies have used a variety of methods to understand how children experience travel. For example, by interviewing children, Ramanathan et al. (2014) found that those who cycle or walk to school feel happier and more excited than those who travel passively (i.e., by car). The same study also showed how passive travel makes children feel rushed and at the same time tired. A large body of research has additionally demonstrated that independent travel is linked with children's psychological development, including increased self-esteem and confidence (e.g., Hillman et al. 1990; Kyttä 2004; Mitra et al. 2014). Zwerts et al. (2010) asked children living in Flanders how they perceived their travel. When these children made additional comments in a questionnaire about their travel, they indicated a positive feeling of responsibility relating to their travel: "I feel tall when I'm walking alone", "I can do what I want when I'm alone", and "I like it when my mum trusts me". For biking and walking, children further highlighted the enjoyment of experiencing nature. Another area of research focuses on social interactions during travel (e.g., Goodman et al. 2014; Waygood et al. 2017), showing the importance of friends for experiencing the journey positively; when interviewed, 9-year-old children said that if a friend joined them in the car they would enjoy the journey (Barker 2009). In contrast, children who travelled by car with their parents and siblings said that they would rather travel independently. However, children express some positive aspects of car travel in that it provides the space and opportunity for both play and conversation - but again - preferably with friends (Barker 2009). In addition to emotional/affective experiences, children also evaluate the quality of their travel. Westman et al. $(2013,2016)$ showed how children rated car travel as having a lower travel quality than active modes while the school bus was experienced as working very well and being of a high standard. Thus, research has so far shown that children are influenced by travel in that it can be experienced as stressful, joyful, or boring, but also as being of high or low quality. However, studies of children's travel experiences have used different methodologies, making it difficult to draw comparisons or conclusions from their travel experiences. Therefore, one contribution made by this study is to obtain specific input from children's cognitive and affective school travel experiences using any type of travel mode and a standardized measure.

Something that has received considerably less attention in research is whether or not travel experiences are associated with children's life satisfaction. In the present study, we address this shortcoming by measuring (i) satisfaction with children's school travel using the Satisfaction with Travel Scale (Ettema et al. 2011; Friman et al. 2013) adapted for children, including both cognitive and affective evaluations, and (ii) children's life satisfaction using the dimensions of the Brief Multidimensional Students' Life Satisfaction Scale (Seligson et al. 2003). The remainder of this article is structured as follows: First, we present the Satisfaction of Travel Scale, its components, and how it has been modified to suit children's vocabulary. We then focus on the association between travel and life satisfaction. In the second section, we present the methodology of our research and delineate the statistical analyses utilized in our investigation. Next, we describe the results of our field study and provide empirical evidence of the 
association between children's life satisfaction and their satisfaction with school travel. Last, we conclude our work by highlighting its theoretical and practical implications, acknowledging its limitations, and offering avenues for future research.

\subsection{The Satisfaction with Travel Scale}

Experienced utility (Kahneman et al. 1997) is a useful concept for understanding evaluations relating to satisfaction with travel, and its wider relevance to wellbeing (Ettema et al. 2010). For this reason, it is essential to develop an appropriate measurement instrument for detecting children's travel experiences. The STS (Ettema et al. 2011 ) is an instrument that is available, designed to include both affective and cognitive components relating to daily travel. The nine-item scale has three subscales involving cognitive evaluations (e.g. low vs. high standard) and affective evaluations concerning positive deactivation (e.g. stressed vs. relaxed) and positive activation (e.g. bored vs. excited). The STS has several advantages, e.g. its brevity (it includes only nine items), its focus on both general quality and the affective experiences of the journey, making it suitable to use when comparing travel experiences using different travel modes. The STS is available in an adult version; however, in this study, we investigate the psychometric properties of the modified version for school-age children (Westman et al. 2016).

The factor structure of the STS has been variously evaluated by bus users, car drivers, and active mode users (Friman et al. 2013; Ettema et al. 2013; Thomas and Walker 2015; De Vos et al. 2015; Olsson et al. 2013; Ye and Titheridge 2016). The results obtained have generally supported the three-factor structure proposed by Ettema et al. (2010). Scale reliability, as measured by internal consistency coefficients such as Cronbach's alpha, is generally moderate-to-good (e.g., Friman et al. 2013).

In Table 1, the nine items of the original STS are visualized alongside the adapted child version STS-C. As can be seen, in the Children's Satisfaction with Travel Scale (STS-C), six adjectives in four of the original nine items have been adjusted to make them more suitable for children's vocabulary. Given this qualitative difference between the child version and the adult version of the STS, it is important to thoroughly evaluate the validity and reliability of the version for school children.

In order to investigate the psychometric properties of the STS-C, this study evaluates its factor structure and internal consistency. Past research has indicated a three-factor solution regarding adult travel experiences. We expect children's travel experiences to be constructed in the same way and we test the original three-factor model proposed by Friman et al. (2013).

\subsection{Travel and Life Satisfaction}

Life satisfaction refers to global cognitive judgments regarding one's life (Pavot et al. 1991) and is considered an important indicator of psychological wellbeing. Though life satisfaction has been studied far less in children than in adults, research has still recognized five domains important to children's and adolescents' life satisfaction; i.e. self, school, friends, family, and living environment (Seligson et al. 2003). In a theoretical model developed by Ettema et al. (2010), it is suggested that, among adults, life satisfaction is also related to their daily travel since a journey can facilitate attendance at important activities, as well as elicit positive and negative affect. For children, travel is 
Table 1 Adult (STS) and child (STS-C) versions of the satisfaction with travel scale

\begin{tabular}{|c|c|c|c|c|c|}
\hline $\begin{array}{l}\text { STS } \\
\text { Original scale for adults }\end{array}$ & & & \multicolumn{3}{|c|}{$\begin{array}{l}\text { STS-C } \\
\text { Adapted scale for children }\end{array}$} \\
\hline $\begin{array}{l}\text { STS-PD } \\
\text { (positive deactivation) }\end{array}$ & & & \multicolumn{3}{|c|}{$\begin{array}{l}\text { STS-C/PD } \\
\text { (positive deactivation) }\end{array}$} \\
\hline very hurried & - & very relaxed & $n c$ & - & $n c$ \\
\hline very worried & - & very confident & $n c$ & - & very carefree \\
\hline very stressed & - & very calm & $n c$ & - & $n c$ \\
\hline $\begin{array}{l}\text { STS-PA } \\
\text { (positive activation) }\end{array}$ & & & \multicolumn{3}{|c|}{$\begin{array}{l}\text { STS-C/PA } \\
\text { (positive activation) }\end{array}$} \\
\hline very tired & - & very alert & $n c$ & - & $n c$ \\
\hline very bored & - & very enthusiastic & $n c$ & - & very interested \\
\hline very fed up & - & very engaged & very spiritless & - & very excited \\
\hline $\begin{array}{l}\text { STS-CE } \\
\text { (cognitive evaluation) }\end{array}$ & & & \multicolumn{3}{|c|}{$\begin{array}{l}\text { STS-C/CE } \\
\text { (cognitive evaluation) }\end{array}$} \\
\hline the worst imaginable & - & the best imaginable & $n c$ & - & $n c$ \\
\hline very low standard & - & very high standard & really useless & - & really excellent \\
\hline worked very poorly & - & worked very well & $n c$ & - & $n c$ \\
\hline
\end{tabular}

$n c$ indicates that the item used in the adult version has not been changed

an activity enabling them to participate in and contribute to the community, providing them with opportunities to freely move from one place to another (Waygood et al. 2017). These theoretical relationships have been confirmed in studies of adults (e.g. Jakobsson Bergstad et al. 2011, 2012; Olsson et al. 2013, see also reviews by De Vos et al. 2013; Ettema et al. 2016), where active travel in particular seems beneficial to wellbeing. However, the question remains of whether or not the model proposed by Ettema et al. (2010) is applicable to children. A recent integrative review (Waygood et al. 2017) focuses on the means by which transport influences children's wellbeing, identifying five main domains of wellbeing relating to transport; i.e. physical, psychological, cognitive, social, and economic. The review further shows that transport plays a role in all these domains of children's wellbeing. Most of the identified benefits of travel are associated with active and independent travel, whereas the most negative impact is associated with road traffic (e.g., crashes, pollution, and noise). Although an existing body of international research supports the notion that travel is important to children's wellbeing, it is clear that research in this area is in its infancy (Waygood et al. 2017).

Swedish children are generally satisfied with their lives. However, psychological and somatic symptoms (e.g., headaches, depression, and insomnia) have been increasing among schoolchildren since the mid-eighties (Public Health Agency of Sweden 2014). Self-reported mental and somatic complaints are now higher among teenagers in Sweden than among children living in other countries (WHO 2016). At the same time, mode use has changed from being predominantly active and independent to being supervised through private car travel (Schmidt and Neergaard 2007). Daily travel may not only be significantly important to adults' wellbeing but also to young people's.

The present study has two aims: (i) to examine the psychometric properties of a child version of STS (referred to as STS-C), and (ii) to test an expected positive relationship 
between travel satisfaction and life satisfaction among children, such as that previously found among adults. Furthermore, we also investigate if this relationship varies with travel mode (i.e. active mode, car, or school bus).

\section{Method}

\subsection{Setting}

This study was carried out at five public schools in Värmland County (approximately 273,000 residents), in southwest Sweden. Inclusion of these five schools was based on differences in travel distances (between students' homes and school), size (numbers of students), and sociodemographic. Differences in distances between school and home varied in median distance (maximum) $4.5 \mathrm{~km}$ and (minimum) $2 \mathrm{~km}$, which made a variety of travel modes possible. The number of students differed between 450 and 35 . A majority of the students lived in households where the parents lacked a university degree (63\%). Average income in the household was approximately 4385 Euro. The family sociodemographic factors conform to the country statistics (Statistics Sweden 2016).

\subsection{Participants and Procedure}

In the 2012-2013 academic year, the school principals at five schools were contacted and approved of the study. After approval, students aged 10-15 $(M=12.29)$ were invited in school to participate in this study. In each class immediately before the first morning lesson, a research assistant verbally informed that participation was voluntary. The students were also informed about the aims of the study and handling of data. The information was given while the students were asked to complete another survey whose results are reported in Westman et al. (2016). Data for this study were collected later in the afternoon by the assistance of the teacher in each class. The research was conducted in accordance with approved research protocols following APA Ethical Guidelines for Research (www.apa.org/ethics/code). This procedure ensured that the students were informed about confidentiality, the right to decline to participate, and to withdraw once participation has begun. Agreement from parents was a necessary prerequisite. Thus, before inviting the students, information letters were sent to the parents by post with a consent form to sign and return. Non-responding households were contacted by phone in order to obtain required consent from as many as possible. Only three parents refused to let their children participate. Data was obtained for 345 children (47.8\% girls).

\subsection{Questionnaire}

Questions about satisfaction with travel to school ${ }^{1}$ were asked (see Table 1), accompanied by instructions that read as follows: Think about the particular moment when you

\footnotetext{
${ }^{1}$ The data collected for this study is part of a larger project relating to children's travel and cognitive performance. The STS-C, mode, gender and age variables presented here have been analyzed and published in Westman et al. (2016), where the focus was on differences between gender, age and mode as regards experiences, mood and cognitive performance. Here, we reanalyze the STS-C data in order to assess the psychometric properties and to relate this to previously unpublished data on children's life satisfaction.
} 
travelled to school this morning. Tick the box that best describes your experience. How did you feel? A child-adapted version of the STS was used. A pilot study was conducted to assess the understandability of the wording and the adjectives used in the original STS for adults. Based on the results of the pilot study, some of the adjective pairs defining the rating scales were slightly altered to better suit children's vocabulary (see Table 1). Three numerical five-point rating scales (1-5) were used to assess the cognitive quality evaluation (STS-C/CE) and the two orthogonal affect dimensions; STS-C/PA represented by boredom/excitement, and STS-C/PD represented by stress/relaxation.

Life satisfaction was measured using the dimensions identified in the Brief Multidimensional Students' Life Satisfaction Scale (Seligson et al. 2003), with each of the five specific domains (self, school, friends, family, and living environment) being represented by one question. The questions were phrased thus: "I'm satisfied with [myself / my school experience / my friendship / my family / where I live]" and rated on five-point scales ranging from $1=$ do not agree at all to $5=$ completely agree.

Information regarding age, gender, and mode-use to school was also collected. Mode-use was categorized as active travel if using a bike, in-lines, kick-bike, or skateboard, or walking $(N=89)$, as school bus if using either regular public transport or an assigned school bus $(N=128$, of which 48 went by public transport), or as car $(N=106)$. Nineteen children indicated using more than one mode on the same trip to school while three did not answer the mode question at all, with these being excluded from further analyses.

\section{Statistical Analyses}

Data was analyzed using partial least squares structural equation modeling (PLS-SEM) using the SmartPLS 3.0 software (Ringle et al. 2015). As an initial step, the STS-C was modeled as a second-order formative construct and we applied a two-step approach during which the measurement models (first-order and second-order constructs) were examined. We then assessed the validity and reliability of the measure of children's life satisfaction. Following this, a structural latent variable model (Anderson and Gerbing 1988), with STS-C, age, gender, and life satisfaction (see Fig. 1), was assessed using the repeated indicator approach in order to estimate the structural (hierarchical) latent variable model (Becker et al. 2012). Finally, multi-group analyses were performed to assess whether or not any differences could be observed between modes as regards the significant paths in the structural model.

PLS-SEM is a robust method to analyze small-sample data (Hair et al. 2017). It does not require nor assume that data is normally distributed, implying that parametric significance tests (such as in regression analyses) cannot be applied to test whether relationships (path coefficients) are significant. Instead, PLS-SEM relies on a nonparametric bootstrap procedure to test the significance of estimated path coefficients. In bootstrapping, randomly drawn observations from the original set of data are used to create subsamples. This process is repeated until a large enough number of random subsamples has been created (5000 is recommended). The parameter estimates (e.g., path coefficients) estimated from the subsamples are then used to derive standard errors. With this information, t-values are calculated to assess each estimate's significance (Hair et al. 2017). 


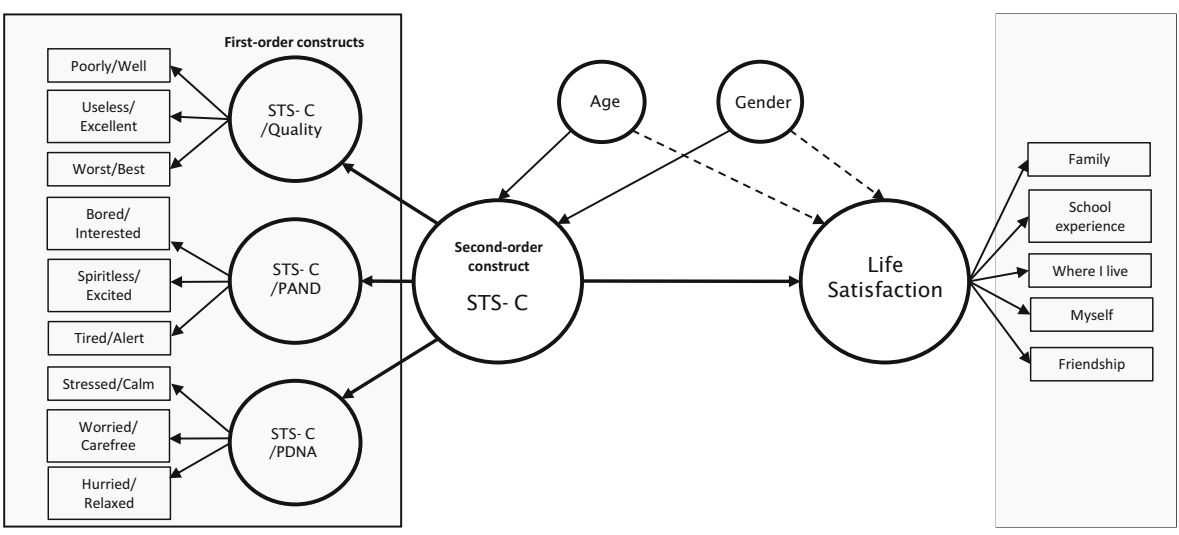

Fig. 1 Structural latent variable model of the relationship between satisfaction with travel and life satisfaction among children

Since life satisfaction data have previously been observed to be non-normally distributet (see for instance Cummins 2003; Diener and Diener 1996), PLSSEM was considered as the most appropriate statistical procedure. Indeed, and as can be seen in Table 2, some of the variables in our model did not meet the formal criteria of normal distribution (skewness and kurtosis); especially variables related to life satisfaction.

Table 2 Mean, Standard deviation, range, skewness and kurtosis of the items in Children's Satisfaction with Travel Scale and the Brief Multidimensional Students' Life Satisfaction Scale

\begin{tabular}{|c|c|c|c|c|c|c|c|}
\hline & $\mathrm{N}$ & Min & Max & Mean & $\mathrm{Sd}$ & Skewness & Kurtosis \\
\hline \multicolumn{8}{|c|}{ STS-C/CE (High/Low Quality) } \\
\hline Poorly/Well & 342 & 2 & 5 & 4.62 & .67 & -1.73 & 2.38 \\
\hline Useless/Excellent & 341 & 1 & 5 & 3.95 & 1.02 & -.77 & .11 \\
\hline Worst/Best & 342 & 1 & 5 & 3.79 & .89 & -.44 & .20 \\
\hline \multicolumn{8}{|c|}{ STS-C/PD (Stress/Relaxation) } \\
\hline Hurried/Relaxed & 340 & 1 & 5 & 4.69 & .64 & -2.24 & 5.48 \\
\hline Worried/Carefree & 340 & 1 & 5 & 4.26 & .94 & -1.25 & 1.21 \\
\hline Stressed/Calm & 341 & 1 & 5 & 4.17 & 1.04 & -1.31 & 1.24 \\
\hline \multicolumn{8}{|c|}{ STS-C/PA (Boredom/Excitement) } \\
\hline Spiritless/Excited & 338 & 1 & 5 & 3.82 & .91 & -.42 & -.19 \\
\hline Tired/Alert & 341 & 1 & 5 & 2.98 & 1.30 & .02 & -1.07 \\
\hline Bored/Interested & 341 & 1 & 5 & 3.10 & 1.19 & -.18 & -.70 \\
\hline \multicolumn{8}{|c|}{ Brief Multidimensional students' life satisfaction scale } \\
\hline My family & 330 & 1 & 5 & 4.71 & .68 & -2.73 & 7.57 \\
\hline Where I live & 330 & 1 & 5 & 4.60 & .80 & -2.48 & 6.58 \\
\hline My friendship & 329 & 1 & 5 & 4.55 & .73 & -1.82 & 3.47 \\
\hline Myself & 329 & 1 & 5 & 4.44 & .89 & -1.83 & 3.31 \\
\hline My school experience & 330 & 1 & 5 & 4.16 & .99 & -1.08 & .39 \\
\hline
\end{tabular}




\section{Results}

\subsection{Measurement Model Analysis}

\subsubsection{First-Order Construct Level of the STS-C}

As suggested by Hair et al. (2013), we used convergent validity, reliability indicators, and discriminant validity to assess the measurement model (e.g., the first-order constructs). Convergent validity was evaluated using the factor loadings and the average variance extracted (AVE). ${ }^{2}$ During initial analysis, all the indicators had significant factor loadings above the required threshold (see Table 3) and the AVEs of all the constructs were well above 0.50 (Fornell and Larcker 1981), confirming a sufficient level of convergent validity.

The reliability of the constructs was assessed according to composite reliability (CR). Table 3 shows that the $\mathrm{CR}$ of all the constructs exceeded the recommended value of 0.708 (Hair et al. 2013), providing strong support for construct reliability.

Next, we tested the discriminant validity of the measured construct using the heterotrait-monotrait (HTMT) ratio of correlations (Henseler et al. 2015). The results presented in Table 4 illustrate that that, although the HTMT for Boredom vs Quality (.91) slightly exceeded the recommended threshold of .90, the confidence intervals were below 1.0, which is in line with the requirements regarding discriminant validity.

\subsubsection{Second-Order Construct Level of the STS-C}

Table 5 illustrates the weights of the first-order constructs on the second-order construct. The significance of the path model relationships among the constructs was determined using a bootstrapping procedure, with a resample of 5000. All three firstorder constructs were significantly associated with satisfaction with travel. Boredom almost had the same positive beta weight as quality, while quality and boredom had slightly higher positive weights than stress. The variance inflation factor (VIF), measuring the degree of multi-collinearity, was calculated. The results (displayed in Table 5) revealed minimal multi-collinearity between the three constructs of satisfaction with travel, ranging from 1.367 to 2.063 , far below the common cut-off threshold of 5.0 (Hair et al. 2013). This denoted that the three constructs of satisfaction with travel were independent of each other.

\subsubsection{Validity and Reliability of Life Satisfaction}

The convergent validity of the latent construct life satisfaction, consisting of five items was evaluated using the factor loadings and the average variance extracted (AVE). All the indicators had significant factor loadings (.65-.81), while the AVE (.54) was above the required threshold (Fornell and Larcker 1981), showing a sufficient level of convergent validity. Composite reliability (.85) provided further support for strong construct reliability. The children were generally satisfied with their lives $(\mathrm{M}=4.5[\mathrm{SD}=0.6])$.

\footnotetext{
${ }^{2}$ During an initial analysis, the convergent validity of all nine items as one latent construct was tested. As AVE only reached 0.41 , convergent validity was considered insufficient.
} 
Table 3 Validity and reliability of first-order constructs

\begin{tabular}{llllll}
\hline First-order constructs & Measurement items & Measures & Factor loadings & CR & AVE \\
\hline STS-C/CE & Poorly/Well & Reflective & 0.778 & .839 & .635 \\
(High/Low Quality) & Worst/Best & & 0.792 & & \\
& Useless/Excellent & & 0.820 & & \\
STS-C/PD & Stressed/Calm & Reflective & 0.776 & .815 & .595 \\
(Stress/Relaxation) & Worried/Carefree & & 0.705 & & \\
& Hurried/Relaxed & & 0.829 & & \\
STS-C/PA & Bored/Interested & Reflective & 0.832 & .856 & .665 \\
(Boredom/Excitement) & Spiritless/Excited & & 0.804 & & \\
& Tired/Alert & & 0.809 & & \\
\hline
\end{tabular}

\subsection{Structural Latent Variable Model}

After confirming that the construct measures had been valid and reliable, our next step was to evaluate the structural model. We assessed the significance of the path model relationships between the constructs using a bootstrapping procedure with a resample of 5000. Twelve participants did not respond to any of the life satisfaction questions and were hence removed from the analyses. For the other variables with only few missing data ( 0 to 4 for each varaible), we followed advice suggested by Hair et al. 2017, and used a mean replacement procedure. The standardized root mean square residual (SRMR) (Henseler et al. 2015) and $\mathrm{RMS}_{\text {theta }}$ were used to assess the approximate model fit. The calculated value of SRMR was 0.079 , indicating an acceptable model fit (recommended cut-off value 0.08; Hu and Bentler 1999), whereas $\mathrm{RMS}_{\text {theta }}$ was 0.18 , slightly above the recommended threshold value $(0.12)$ (Hair et al. 2017). ${ }^{3}$

As Fig. 2 shows, gender $(\beta=0.11 ; t=2.12 ; p<0.05)$ and age $(\beta=-.23 ; t=4.30$; $p<0.01$ ) had significant direct effects on the STS-C, whereby boys rated the STS-C higher than girls, and older children rated the STS-C lower than younger children. It can furthermore be seen that the STS-C had a strong and significant effect on life satisfaction $(\beta=0.44 ; t=9.18 ; p<0.01)$. No direct effects on life satisfaction could be observed for gender or age. However, indirect effects on Life satisfaction, when using the STS-C, were found as regards both age $(\beta=-0.10 ; t=3.99 ; \mathrm{p}<0.01)$ and gender $(\beta=0.05 ; t=2.01 ; p<0.05)$.

\subsection{PLS Multi-Group Analyses (MGA)}

To assess whether or not the paths observed in the structural model are applicable to children who use different modes, pairwise multi-group analyses were performed for children categorized as traveling by car, active mode, or school bus. During PLS-MGA,

\footnotetext{
${ }^{3}$ It is worth noting that there is an ongoing debate about appropriate model fit measures and threshold levels for PLS-SEM models, as conventional model fit indices may not be perfectly applicable. There is therefore a call for more research on this issue (Hair et al. 2017).
} 
Table 4 Heterotrait-monotrait (HTMT) ratio of correlations

Confidence interval of Heterotrait-monotrait (HTMT)

Construct

Low/High Quality

(STS-C/CE)

Boredom/Excitement

(STS-C/PA)

Stress/Relaxation

$.61-.85$

$.46-.70$

(STS-C/PD)

Boredom/Excitement

$.82-.98$

(STS-C/PA)

the difference between each path coefficient in the structural model is statistically tested between different groups (in this case defined by the three different modes), using a bootstrap procedure with 5000 replicates. The results revealed that there was a stronger relationship between the STS-C and life satisfaction in those traveling by active mode compared to those traveling by car (path diff $=0.23, p<.05$ ) and school bus (path diff $=0.22, \mathrm{p}<.05$ ). No significant path differences were observed between car and school bus. The significant paths between age and the STS-C and gender and the STS-C did not vary significantly between the three modes.

\section{Discussion}

In this paper, we first evaluated the psychometric properties of a new scale in order to measure children's stated travel experiences; the Satisfaction with Travel Scale for Children (STS-C). Our second aim was to investigate the relationship between travel satisfaction and life satisfaction among children. Addressing the first aim, we conclude that the scale was internally reliable and had a sound construct validity. Consistent with previous findings among adults (Friman et al. 2013), our analyses yielded a one-factor second-order measurement model with three first-order constructs (cognitive evaluation, positive activation, and positive deactivation). These results showed that children aged between 10 and 15 distinguished between constructs when asked about their travel experiences. Research shows that two dimensions underpin an experience: $(a)$ the affective dimension and $(b)$ the cognitive dimension. In order to fully measure and understand how children perceive their journeys, it is thus important to capture both the affective (e.g. stress and boredom) and the cognitive evaluations (e.g. perceived

Table 5 Weights, t-statistics, and variance inflation factor (VIF) of the first-order constructs on the designated second-order construct

\begin{tabular}{llllr}
\hline Second-order construct & First-order constructs & Weight & $t$-value & VIF \\
\hline Satisfaction with travel for & STS-C/CE (Low/High Quality) & .428 & 38.29 & 2.063 \\
children (STS-C) & STS-C/PD (Stress/Relaxation) & .331 & 25.53 & 1.367 \\
& STS-C/PA (Boredom/Excitement) & .435 & 39.65 & 1.875 \\
\hline
\end{tabular}




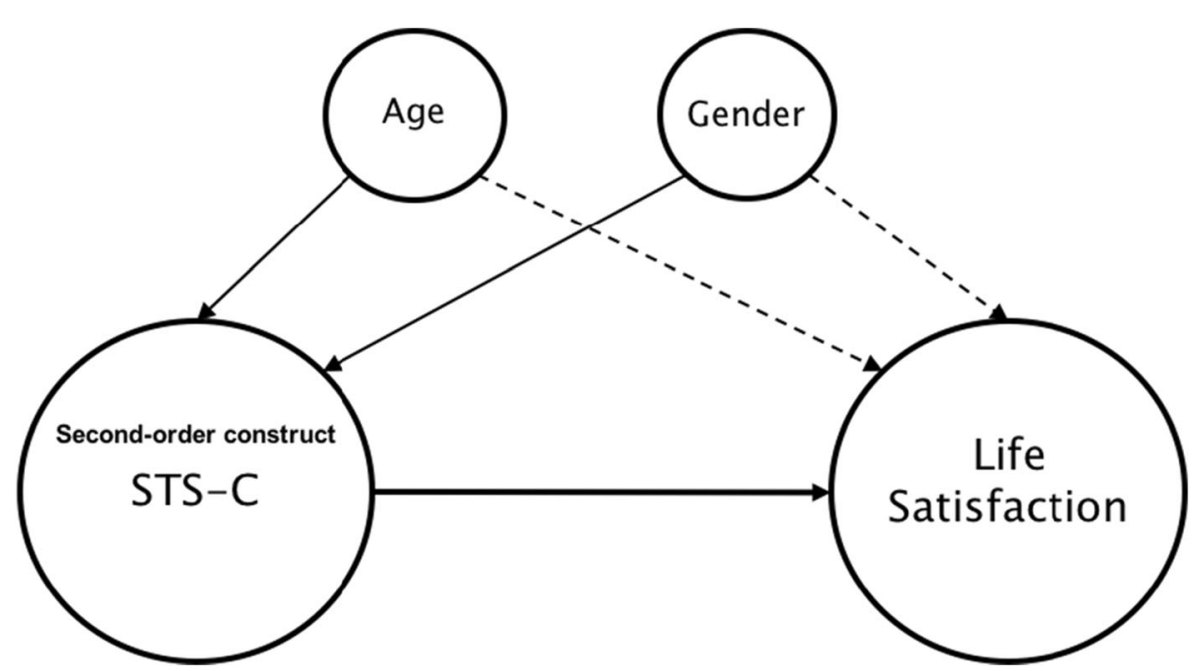

Fig. 2 Significant direct (solid lines) and indirect (dashed lines) effects of travel satisfaction, gender, and age on life satisfaction

quality) of the travel experience (Ettema et al. 2012; Jones et al. 2012; Westman et al. 2016). We propose that the newly-developed and tested STS-C can be an easy-to-use tool for capturing these important dimensions of children's travel experiences.

Although the analyses provide support for a sound scale for measuring children's travel satisfaction, one could still ask how reliable the scale would be in other contexts and with other samples, e.g. in a different cultural setting where the meanings of the adjectives can diverge slightly. Affectively charged words may have slightly different meanings in different cultures; an issue that may be even more pronounced among children. Therefore, considerable attention should be paid to the items used. Future research may want to investigate travel experiences under different circumstances and we welcome research that translates the scale to other languages in order to further scrutinize its validity. The original adult version of the scale (STS) has been successfully translated into other languages (De Vos et al. 2015; Ettema et al. 2013), with positive results. Likewise, in the present study, we adjusted the scale for children aged between 10 and 15, but we cannot say how applicable it would be to younger children. Perhaps the adjective pairs in the scale could be accompanied by mood icons, especially when seeking to investigate the travel experiences of very young children.

In the present study, the scale was applied to school travel but may very well be used, as with the adult version of the scale, for any kind of travel (e.g., leisure trips, holiday trips, shopping trips). The scale could also be used as a generic measure of children's overall satisfaction with travel in general. However, some care should be taken with generic measures directed at children since these would require them to be able to correctly remember, add up, and calculate their average satisfaction with a large number of journeys in different activities and contexts, e.g. independently traveling to see friends, travel on public transport to sporting activities, traveling by car to see relatives, and school travel. One question that remains to be answered concerns the age at which children would be able to correctly manage this task. In our study, only school travel was measured, thus minimizing the risk of memory distortion. 
Turning to our second aim, our results showed that children's school travel experiences were important for their life satisfaction, corresponding with results from adult populations (Olsson et al. 2013). The findings further showed that the relationships varied slightly between modes, where it was stronger among children traveling by active mode than among those traveling by school bus or car. Children who travel actively often do so in the company of friends, which could help explain the distinct findings between modes; children particularly enjoy active travel because of the opportunity to interact with friends (Barker 2009; Siedlecki et al. 2014). An additional finding was that younger children, and boys, were more satisfied with their journeys than older children, and girls, something which also had an indirect effect on life satisfaction. One explanation for this age effect could be the fact that adolescence is a period of flux when previously satisfied young people generally tend to become less satisfied and less frequently have positive emotions (Larson and Richards 2000; Pipher 1994), something which is even more pronounced in teenage girls (Nolen-Hoeksema and Girgus 1994). These findings further support the significant relationship between children's travel experiences and their satisfaction with life, and how the experience and satisfaction varies with travel mode, age, and gender. There may also be additional transport-related factors which are of importance to children's life satisfaction and which were not measured in the present study. One such factor is independent travel, which enables social interaction with friends - an important aspect of children's wellbeing (Waygood et al. 2017). Another factor is travel time, which allows children to engage in activities that influence certain aspects of their wellbeing (Westman et al. 2016). We welcome future research aimed at investigating additional factors that may affect children's wellbeing and include them in the model.

Acknowledgements Financial support was obtained through grant 2014-05335 from the Swedish Governmental Agency for Innovation Systems (VINNOVA). We thank Christian Ringle and James Gaskin for valuable comments.

Open Access This article is distributed under the terms of the Creative Commons Attribution 4.0 International License (http://creativecommons.org/licenses/by/4.0/), which permits unrestricted use, distribution, and reproduction in any medium, provided you give appropriate credit to the original author(s) and the source, provide a link to the Creative Commons license, and indicate if changes were made.

\section{References}

Anderson, J. C., \& Gerbing, D. W. (1988). Structural equation modeling in practice: A review and recommended two-step approach. Psychological Bulletin, 103(3), 411-423.

Barker, J. (2009). Driven to distraction?: Children's experiences of car travel. Mobilities, 4(1), 59-76. https://doi.org/10.1080/17450100802657962.

Becker, J. M., Klein, K., \& Wetzels, M. (2012). Hierarchical latent variable models in PLS-SEM: Guidelines for using reflective-formative type models. Long Range Planning, 45(5/6), 359-394. https://doi.org/10.1016/j.lrp.2012.10.001.

Cummins, R. A. (2003). Normative life satisfaction: Measurement issues and a homeostatic model. Social Indicators Research, 64(2), 225-256.

De Vos, J., Schwanen, T., Van Acker, V., \& Witlox, F. (2013). Travel and subjective well-being: A focus on findings, methods and future research needs. Transportation Reviews, 33(4), 421-442. https://doi.org/10.1080/01441647.2013.815665. 
De Vos, J., Schwanen, T., Van Acker, V., \& Witlox, F. (2015). How satisfying is the scale for travel satisfaction? Transportation Research Part F: Traffic Psychology and Behaviour, 29, 121-130. https://doi.org/10.1016/j.trf.2015.01.007.

Diener, E., \& Diener, C. (1996). Most people are happy. Psychological Science, 7(3), 181-185.

Ettema, D., Gärling, T., Olsson, L. E., \& Friman, M. (2010). Out-of-home activities, daily travel, and subjective well-being. Transportation Research Part A, 44(9), 723-732. https://doi.org/10.1016/j. tra.2010.07.005.

Ettema, D., Gärling, T., Eriksson, L., Friman, M., Olsson, L. E., \& Fujii, S. (2011). Satisfaction with travel and subjective well-being: Development and test of a measurement tool. Transportation Research Part F, 14(3), 167-175. https://doi.org/10.1016/j.trf.2010.11.002.

Ettema, D., Friman, M., Gärling, T., Olsson, L. E., \& Fujii, S. (2012). How in-vehicle activities affect work commuters' satisfaction with public transport. Journal of Transport Geography, 24, 215-222.

Ettema, D., Gärling, T., Olsson, L. E., Friman, M., \& Moerdijk, S. (2013). The road to happiness: Measuring Dutch car drivers' satisfaction with travel. Transport Policy, 27, 171-178. https://doi.org/10.1016/j. tranpol.2012.12.006.

Ettema, D., Friman, M., Gärling, T., \& Olsson, L. E. (2016). Travel mode use, travel mode shift and subjective well-being: Overview of theories, empirical findings and policy implications. In D. Wang \& H. Shenjing (Eds.), Mobility, sociability and well-being of urban living (pp. 129-150). Berlin: Springer.

Fornell, C., \& Larcker, D. F. (1981). Evaluating structural equation models with unobservable variables and measurement error. Journal of Marketing Research, 18(1), 39-50. https://doi.org/10.2307/3151312.

Friman, M., Satoshi, F., Ettema, D., Gärling, T., \& Olsson, L. E. (2013). Psychometric analysis of the satisfaction with travel scale. Transportation Research Part A: Policy and Practice, 48, 132-145. https://doi.org/10.1016/j.tra.2012.10.012.

Goodman, A., Jones, A., Roberts, H., Steinbach, R., \& Green, J. (2014). 'We can all just get on a Bus and Go’: Rethinking independent mobility in the context of the universal provision of free bus travel to young Londoners. Mobilities, 9(2), 275-293.

Hair, J. F., Ringle, C. M., \& Sarstedt, M. (2013). Editorial - partial least squares structural equation modeling: Rigorous applications, better results and higher acceptance. Long Range Planning, 46(1-2), 1-12. Available at SSRN: https://ssrn.com/abstract=2233795

Hair, J. F., Hult, G. T., Ringle, C. M., \& Sarstedt, M. (2017). A primer on partial least squares structural equation modeling ( 2 nd ed.). Thousand Oaks: Sage.

Henseler, J., Ringle, C. M., \& Sarstedt, M. (2015). A new criterion for assessing discriminant validity in variance-based structural equation modeling. Journal of the Academy of Marketing Science, 43(1), 115135. https://doi.org/10.1007/s11747-014-0403-8.

Hillman, M., Adams, J., \& Whitelegg, J. (1990). One false move...: A study of children's independent mobility. London: PSI.

Hu, L., \& Bentler, M. P. (1999). Cutoff criteria for fit indexes in covariance structure analysis: Conventional criteria versus new alternatives. Structural Equation Modeling: A Multidisciplinary Journal, 6(1), 1-55. https://doi.org/10.1080/10705519909540118.

Jakobsson Bergstad, C., Gamble, A., Hagman, O., Polk, M., Gärling, T., Ettema, D., Friman, M., \& Olsson, L. E. (2011). Subjective well-being related to satisfaction with daily travel. Transportation, 38, 1-15. https://doi.org/10.1007/s11116-010-9283-Z.

Jakobsson Bergstad, C., Gamble, A., Hagman, O., Polk, M., Gärling, T., Ettema, D., Friman, M., \& Olsson, L. E. (2012). Influences of affect associated with routine out-of-home activities on subjective well-being. Applied Research Quality Life, 7(49). https://doi.org/10.1007/s11482-011-9143-9.

Jones, A., Steinbach, R., Roberts, H., Goodman, A., \& Green, J. (2012). Re-thinking passive transport: Bus fare exemptions and young people's wellbeing. Health \& Place, 18(3), 605-612.

Kahneman, D., Wakker, P. P., \& Sarin, R. (1997). Back to Bentham? Explorations of experienced utility. The Quarterly Journal of Economics, 112(2), 375-406. https://doi.org/10.1162/003355397555235.

Kyttä, M. (2004). The extent of children's independent mobility and the number of actualized affordances as criteria for child-friendly environments. Journal of Environmental Psychology, 24, 179-198.

Larson, R. W., \& Richards, M. H. (2000, July). Changes in daily emotions associated with entry into adolescence for urban African Americans. Paper presented at the biannual meeting of the International Society for the Study of behavioral development. China: Beijing.

Mitra, R., Faulkner, G. E., Buliung, R. N., \& Stone, M. R. (2014). Do parental perceptions of the neighbourhood environment influence children's independent mobility? Evidence from Toronto, Canada. Urban Studies, 51(16), 3401-3419.

Nolen-Hoeksema, S., \& Girgus, J. S. (1994). The emergence of gender differences in depression during adolescence. Psychological Bulletin, 115, 424- 443. 
Olsson, L. E., Gärling, T., Ettema, D., Friman, M., \& Satoshi, F. (2013). Happiness and satisfaction with work commute. Social Indicators Research, 111, 255-263. https://doi.org/10.1007/s11205-012-0003-2.

Pavot, W., Diener, E., Colvin, R. C., \& Sandvik, E. (1991). Further validation of the satisfaction with life scale: Evidence for the cross-method convergence of well-being measures. Journal of Personality Assessment, 57(1), 146-161. https://doi.org/10.1207/s15327752jpa5701_17.

Pipher, M. (1994). Reviving Ophelia: Saving the selves of adolescent girls. New York: Putnam.

Ramanathan, S., O’Brien, C., Faulkner, G., \& Stone, M. (2014). Happiness in motion; emotions, well-being, and active school travel. Journal of School Health, 84(8), 516-523.

Ringle, C. M., Wende, S., \& Becker, J.-M. (2015). SmartPLS 3. Bönningstedt: SmartPLS Retrieved from http://www.smartpls.com.

Schmidt, L., \& Neergaard, K. (2007). Children's and young people's travel habits [Barns och ungdomars resvanor - en resvaneundersökning bland 6-15 åringar i olika stora orter] https://www.trafikverket. se/contentassets/e2d4f3416b4b4a40ab7bcb27f8916874/barns_och_ungdomars_resvanor_trivector_ rapport2007_73.pdf.

Seligson, J. L., Huebner, E. S., \& Valosir, R. F. (2003). Preliminary validation of the brief multidimensional students' life satisfaction scale (BMSLSS). Social Indicators Research, 61, 121-145.

Siedlecki, K. L., Salthouse, T. A., Oishi, S., \& Jeswani, S. (2014). The relationship between social support and subjective well-being across age. Social Indicators Research, 117(2), 561-576.

Statistics Sweden. (2016). Regional descriptives of the Swedish population. Retrieved December 12, 2016 from: http://www.statistikdatabasen.scb.se/pxweb/en

The Public Health Agency of Sweden (2014) [Folkhälsomyndigheten]. Schollchildren's health status in Sweden [Skolbarns hälsovanor i Sverige 2013/2014].

Thomas, G. O., \& Walker, T. (2015). Users of different travel modes differ in journey satisfaction and habit strength but not environmental worldviews: A large-scale survey of drivers, walkers, bicyclists and bus users commuting to a UK university. Transportation Research Part F: Traffic Psychology and Behaviour, 34, 86-93. https://doi.org/10.1016/j.trf.2015.07.016.

Waygood, E. O. D., Friman, M., Olsson, L. E., \& Taniguchi, A. (2017). Transport and child well-being: An integrative review. Travel Behaviour and Society, 9, 32-49. https://doi.org/10.1016/j.tbs.2017.04.005.

Westman, J., Johansson, M., Olsson, L. E., Mårtensson, F., \& Friman, M. (2013). Children’s affective experience of every-day travel. Transport Geography, 29, 95-102.

Westman, J., Olsson, L. E., Gärling, T., \& Friman, M. (2016). Children's travel to school: Satisfaction, current mood, and cognitive performance. Transportation, 44(6), 1365-1382. https://doi.org/10.1007/s11116016-9705-7.

World Health Organization (WHO). (2016). International report from the 2013/2014 survey. Growing up unequal: gender and socioeconomic differences in young people's health and well-being. Health policy for children and adolescents, no. 7. Copenhagen: Denmark.

Ye, R., \& Titheridge, H. (2016). Satisfaction with the commute: The role of travel mode choice, built environment and attitudes. Transportation Research Part D: Transport and Environment. https://doi.org/10.1016/j.trd.2016.06.011.

Zwerts, E., Allaert, G., Janssens, D., Wets, G., \& Witlox, F. (2010). How children view their travel behaviour: A case study from Flanders (Belgium). Journal of Transport Geography, 18(6), 702-710. https://doi.org/10.1016/j.jtrangeo.2009.10.002. 